\title{
OS IMPACTOS DO PROGRAMA DE RESIDÊNCIA PEDAGÓGICA NA ESCOLA-CAMPO IFRN IPANGUAÇU
}

José Luiz Silva da Costa ${ }^{1}$

\section{PALAVRAS-CHAVE}

Residência Pedagógica;

Escola-Campo IFRN

Ipanguaçu;

Trabalho Docente.

\section{RESUMO}

Este capítulo sinaliza os impactos do Programa de Residência Pedagógica (PRP) na escola-campo IFRN, campus Ipanguaçu. Parte da problematização sobre os desafios e possibilidades da formação docente no Estado contemporâneo em que se percebem professores em meio a um pensar dialético que envolve identificação e desilusão com a docência. $\mathrm{O}$ capítulo percebe a escola pública, por excelência, como um espaço de formação continuada. Analisa o Programa de Residência Pedagógica, seus avanços e dificuldades, na perspectiva de uma política pública necessária para a formação dos docentes destacadamente em função de conciliar a formação continuada e a interação entre licenciandos com o chão da escola. Por fim, evidencia os impactos pedagógicos da implantação e da execução do PRP na escolacampo IFRN Ipanguaçu.

\section{OS DESAFIOS DA FORMAÇÃO INICIAL E CONTINUADA DOCENTE: DIALÉTICA ENTRE IDENTIFICAÇÃO X DESILUSÃO COM A DOCÊNCIA}

A educação é, sem dúvida, uma arma necessária às atuais e futuras gerações para a transformação social. A escola pública, em particular, por seu alcance, seu público e sua missão social é a chave para grandes mudanças no Brasil e no mundo. Porém, a revelia dessa certeza, governos e empresários não a tratam com o seu devido valor. Isso se pode enxergar por meio da precarização das estruturas, no trato dos usuários do sistema público e na formação, capacitação e valorização dos profissionais da educação, entre outros aspectos. A educação que é um direito inalienável, não alçou o voo da consolidação almejada pela sociedade.

Apesar da vontade permanente de mudanças da sociedade civil e do desejo de transformação das estruturas da educação nacional, às políticas para o setor caminham a passos lentos. São necessárias decisões, ações políticas e pedagógicas que incluam a educação, a valorização e o desenvolvimento dos seus profissionais no campo das prioridades.

Para isso, é fundamental um projeto a médio e a longo prazo de políticas estruturais para o campo da educação, destacadamente, com relação a formação continuada e a participação democrática das gestões institucionais.

1 Professor do Instituto Federal de Educação, Ciência e Tecnologia do Rio Grande do Norte. Doutorando do PPGFIL UFRN (Programa de Pós-Graduação em Filosofia da Universidade Federal do Rio Grande Norte). Preceptor do Programa Residência Pedagógica. E-mail: luiz.jose@ifrn.edu.br 
A formação inicial e continuada do docente é fundamental para alicerçar um pilar rígido que sustente o sistema educacional e que crie as condições propícias para o fazer pedagógico inovador e libertador. É no cotidiano da sala de aula e dos ambientes escolares que vão se delineando as integridades dos sujeitos ali envolvidos.

Quando se imagina ou se almeja uma educação universal e transformadora se entende que o investimento na escola pública é um ponto essencial. Para isso, um dos componentes fundamentais compreende a qualidade de vida dos indivíduos que dinamizam a escola.

A questão da formação docente tem seu formato, regras e alcance específicos e, importa lembrar, que há muito tempo vem perdendo a sua identidade e a sua fundamentação. Esse processo de frouxidão de identidade se relaciona fortemente com a desvalorização estrutural da escola pública e da carreira docente.

Dito de outra forma, denunciamos que os cursos de licenciatura não conseguem dar um caráter formativo integral com relação aos desafios que irão enfrentar.

A identidade profissional, o seu caráter de classe, os processos de formação a que devem estar submetidos são fundamentais para repensar a prática do professor e dos que estão em seu caminho formativo. Tal questão é vital sob pena de assistirmos um esvaziamento cada vez maior dos cursos de licenciatura e de vivenciarmos mais amplamente um processo de desmantelamento e de desilusão, ou desidentificação, com o fazer e a carreira do profissional docente.

Desta maneira Pimenta (1997) nos posiciona em tal debate:

(...) a discussão sobre a identidade profissional do professor, tendo como suporte teórico-metodológico a questão dos saberes que constituem a docência e o desenvolvimento dos processos de reflexão docente sobre a prática. É esse caminho que estamos percorrendo, na tentativa de resignificar os processos formativos a partir da reconsideração dos saberes necessários à docência, colocando a prática pedagógica e docente escolar como objeto de análise. (PIMENTA, 1997, p. 1).

Para Tardif (2002) a prática profissional no que tange a atividade docente é fundamental para a vida profissional e o saber-fazer das atividades didáticopedagógicas. A experiência prévia e a imersão no ambiente escolar facilitam e incorporam uma constituição completa do profissional que irá desempenhar as funções de ensino-aprendizagem.

O Programa de Residência Pedagógica se insere nestas tentativas de fomentar uma maior inclusão de práticas educacionais que vincule o licenciando na prática profissional desde o início do seu ciclo formativo. 
Entretanto, este Programa, mesmo com suas colaborações, não se desvincula da agenda neoliberal ${ }^{2}$ no setor da educação que tem precarizado cada vez mais a possibilidade de uma educação crítica e livre.

No capitalismo, educação é vista como "mercadoria" e tende a valorizar estritamente o lucro em detrimento das experiências formativas e da qualidade de aprendizagem dos sujeitos no processo.

No Brasil temos presenciado o avanço do paradigma neoliberal na medida em que os governos endossam Programas que transferem dinheiro do setor público para o privado (FIES, PROUNI)3; que promovem a aprovação de decreto e reformas ${ }^{4}$ que visam a precarização e o desmonte da educação pública; que não se dirigem ao lucro abissal dos conglomerados educacionais como a Kroton, a Estácio, a Laureate e a Unip; que cortam o financiamento da educação superior; que aprovam um projeto de guerra aberta através da censura e de culpabilização de docentes pelo estado crítico em que se encontra a educação pública nacional, entre outros.

As políticas públicas educacionais neoliberais precarizam a função social docente e diminui a sua valorização por meio dos déficits nas carreiras, auxílios, condição de trabalho, entre outros. Urge, portanto, pensar os projetos de formação docente inserindo-os desde a sua formação teórica e prática num debate de valorização do docente e da escola pública.

Os programas de formação docente devem ter compromisso com a defesa da escola pública e a formação continuada dos futuros e atuais docentes.

Para Tardif (2002, p. 65), o fazer docente deve se basear num sincretismo que exige do agente docente "um vasto leque de saberes compostos, ao agir, o professor se baseia em vários tipos de juízos práticos para estruturar e orientar sua atividade profissional".

\footnotetext{
${ }^{2}$ Harvey (2005) descreve o neoliberalismo como sendo "em primeiro lugar uma teoria das práticas político-econômicas que propõe que o bem-estar humano pode ser melhor promovido liberando-se as liberdades e capacidades empreendedoras individuais no âmbito de uma estrutura institucional caracterizada por sólidos direitos a propriedade privada, livres mercados e livre comércio. (...) Além disso, se não existirem mercados (em áreas como a terra, a água, a instrução, o cuidado de saúde, a segurança social ou a poluição ambiental), estes devem ser criados, se necessário pela ação do Estado. Mas o Estado não deve aventurar-se para além dessas tarefas. As intervenções do Estado nos mercados (uma vez criados) devem ser mantidas num nível mínimo, porque, de acordo com a teoria, o Estado possivelmente não possui informações suficientes para entender devidamente os sinais do mercado (preços) e porque poderosos grupos de interesse vão inevitavelmente distorcer e viciar as intervenções do Estado (particularmente nas democracias) em seu próprio beneficio"

${ }^{3}$ Conforme MARTINS (2015) "No setor da Educação Superior Pública programas como REUNI, PROUNI, FIES e Novo ENEM, foram mecanismos implantados pelos governos petistas e que se configuram como formas de sucateamento da universidade pública e adequação às demandas dos organismos multilaterais".

4 As alterações implementadas pela lei $\mathrm{n}^{\circ} 13.415$ de 2017 (com pouca discussão nas instâncias democráticas da educação) alteram substancialmente o ensino médio e a LDB de 1996 (que possibilitou um debate maior com os agentes educacionais e a sociedade civil), e de forma quase direta precarizam os cursos de licenciatura que estão assustados quanto à possibilidade de fechamento de postos de trabalho e recrudescimento de novas entradas em seus cursos. Assim como altera toda a concepção de ensino médio já existente, e desta maneira, modifica a vida e a formação dos que trabalham neste setor.
} 
Diante do pensamento anterior, apresentamos um quadro a seguir que demonstra a diversidade de saberes que concorrem para a vida do professor. Esses saberes se estendem desde a sua formação escolar básica, passam pela formação acadêmica e, principalmente, pela sua longa prática no dia a dia escolar.

Quadro 1: Saberes dos professores

\begin{tabular}{|c|c|c|}
\hline \multicolumn{3}{|c|}{ Os saberes dos professores } \\
\hline Saberes dos professores & $\begin{array}{l}\text { Fontes sociais de } \\
\text { aquisição }\end{array}$ & $\begin{array}{c}\text { Modos de integração no } \\
\text { trabalho docente }\end{array}$ \\
\hline $\begin{array}{l}\text { Saberes pessoais dos } \\
\text { professores }\end{array}$ & $\begin{array}{l}\text { A família, o ambiente } \\
\text { de vida, a educação no } \\
\text { sentido lato, etc. }\end{array}$ & $\begin{array}{l}\text { Pela historia de vida e } \\
\text { socialização primária }\end{array}$ \\
\hline $\begin{array}{l}\text { Saberes provenientes da } \\
\text { formação escolar anterior }\end{array}$ & $\begin{array}{l}\text { A escola primária e } \\
\text { secundária, os estudos } \\
\text { pós-secundários } \\
\text { especializados, etc. }\end{array}$ & $\begin{array}{lll}\text { Pela formação e } & \text { pela } \\
\text { socialização } & & \text { pré- } \\
\text { profissionais } & & \\
\end{array}$ \\
\hline $\begin{array}{l}\text { Saberes provenientes da } \\
\text { formação profissional } \\
\text { para o magistério. }\end{array}$ & $\begin{array}{l}\text { Os estabelecimentos de } \\
\text { formação de } \\
\text { professores, os estágios } \\
\text { e os cursos de } \\
\text { reciclagem, etc. }\end{array}$ & $\begin{array}{l}\text { Pela formação e } \\
\text { profissionalização } \\
\text { instituições de formação de } \\
\text { professores }\end{array}$ \\
\hline \begin{tabular}{|l}
\multicolumn{3}{l}{ Saberes provenientes dos } \\
programas e livros \\
didáticos usados no \\
trabalho
\end{tabular} & $\begin{array}{l}\text { A utilização } \quad \text { das } \\
\text { "ferramentas" dos } \\
\text { professores: } \\
\text { programas, livros } \\
\text { didáticos, cadernos de } \\
\text { exercícios, fichas, etc. }\end{array}$ & $\begin{array}{l}\text { Pela utilização das } \\
\text { "ferramentas" de trabalho, } \\
\text { sua adaptação às tarefas }\end{array}$ \\
\hline $\begin{array}{l}\text { Saberes provenientes de } \\
\text { sua própria experiência } \\
\text { na profissão, na sala de } \\
\text { aula e na docência }\end{array}$ & $\begin{array}{l}\text { A prática do ofício na } \\
\text { escola e na sala de aula, } \\
\text { a experiência dos } \\
\text { pares, etc. }\end{array}$ & $\begin{array}{l}\text { Pela pratica do trabalho e } \\
\text { pela } \\
\text { profissional }\end{array}$ \\
\hline
\end{tabular}

Fonte: Tardif (2002), capítulo 2 do texto: "Saberes docentes e formação profissional".

Neste sentido, o PRP fornece subsídios para a orientação da prática docente já que expõem os residentes a uma série de atividades da prática profissional que os permitem se socializar e acessar aprendizagens sobre a sua futura profissão.

O PRP está de acordo com o último quadro da tabela acima, que aponta que os saberes são constituídos "no ofício da escola e na sala de aula, na experiência dos pares, na prática do trabalho e na socialização profissional".

Conforme Guedes: 


\begin{abstract}
Historicamente, a categoria docente tem sofrido seja com o desprestígio social da profissão, seja por sua descaracterização, ou até mesmo pelas dificuldades evidenciadas no próprio processo de ensino. Há que se entender, nesse contexto, que o professor, em sua trajetória, encontra inúmeros elementos que o impedem de promover essa construção que é social e pessoal. Refletir com o professor sobre sua prática será a oportunidade de efetivar uma análise da construção/desconstrução/reconstrução do seu próprio processo de profissionalização. (GUEDES, 2014, p 4).
\end{abstract}

O desenvolvimento do PRP fornece uma complexa e importante relação entre professores e alunos uma vez que promove a inclusão do residente no ambiente escolar em todos os seus níveis, a saber: preparação de aulas, conhecimentos dos espaços físicos, regência de aulas, reconhecimento de seu local de trabalho, entre outros.

\title{
UMA CLAREIRA SE ABRE: PROGRAMA DE RESIDÊNCIA PEDAGÓGICA UMA QUESTÃO VITAL PARA A FORMAÇÃO DOCENTE?
}

O Programa de Residência Pedagógica (PRP) proposto e fomentado pela Coordenação de Aperfeiçoamento de Pessoal de Nível Superior (CAPES) é apontado no início do ano de 2018 como uma política educacional destinada à formação docente. Tenta se vincular às demandas mais urgentes que objetivam a inserção de residentes no universo da docência, a valorização de licenciandos, a promoção de profissionais docentes, a aproximação entre as instituições de formação docente e as realidades das instituições públicas de educação básica.

O Programa e os seus participantes têm buscado alternativas para a questão das novas formas de aprendizagem e vem aprendendo num processo teórico-prático a produzir metodologias facilitadoras de ensino.

Em seu formato inicial e enquanto projeto, o PRP tenta estabelecer uma dinâmica que busca relacionar e aproximar a universidade nas figuras dos residentes e de professores universitários para atuarem junto aos professores das escolas-campo de educação básica, tentando aprimorar os modelos arcaicos dos estágios curriculares obrigatórios e propiciando uma cultura de diálogo de aprendizagens beneficiando a formação de todos os envolvidos.

Esta dinâmica tem demonstrando avanços, a partir dos inúmeros minicursos, eventos acadêmicos, artigos escritos, feiras científicas e reuniões conjuntas em que se expõem os avanços das manifestações pedagógicas oriundas da diversidade de relações propiciadas.

Consonante Tavares e Santos (2019) afirmam que o programam visa dar sustentação às novas possiblidades das relações professor-aluno proporcionando uma experiência in loco e construtiva que visam objetivar a prática docente dos residentes e construir desde cedo uma identificação com a profissão. 
O programa Residência Pedagógica apresenta-se como uma proposta que visa à valorização da formação inicial de futuros professores, tendo entre seus objetivos promover a imersão ampliada do estudante-professor na realidade escolar, isto é, na escola de educação básica. O PRP tenta superar a dicotomia entre teoria e empiria, que marca historicamente a formação de professores, e busca enfrentar objetivamente o distanciamento entre os espaços da formação e do exercício profissional. (TAVARES, SANTOS; 2019, p. 156)

As instituições que adotaram o Programa têm a finalidade de proporcionar aos residentes licenciandos uma profunda experiência teórico/prática que se expressa na quantidade de horas em preparação, nas reuniões e na sala de aula. A experiência se divide em quatro etapas, a saber: formação inicial, ambientação, imersão e regência. Segue uma síntese das principais delas:

1. Ambientação: etapa de inserção e adequação dos residentes aos espaços formativos escolares. Neste momento o residente participa da vida social da escola e se insere como sujeito daquele lugar. É momento para conhecer a comunidade escolar e a turma que o acolherá.

2. Imersão: etapa em que os professores orientador e preceptor auxiliarão o residente a produzir planejamento, escolha de materiais, avaliação das aulas, suporte aos estudantes.

3. Regência: etapa em que o residente participa de forma direta na mediação de aulas e minicursos, apresentando trabalhos acadêmicos, orientando atividades teórico-práticas, auxiliando na correção de projetos e atividades escolares.

Em seu conjunto, as atividades do Programa perfazem uma jornada de 440 horas que são realizadas na sua integralidade, na relação direta entre residente, orientador e preceptor na sala de aula ou na preparação para ela. Conforme exposto nas indicações que foram assentadas no edital n06/2018 da CAPES que introduz e normatiza o PRP, de acordo com o quadro abaixo:

Quadro 2 : Cronograma de atividades do Programa de Residência Pedagógica

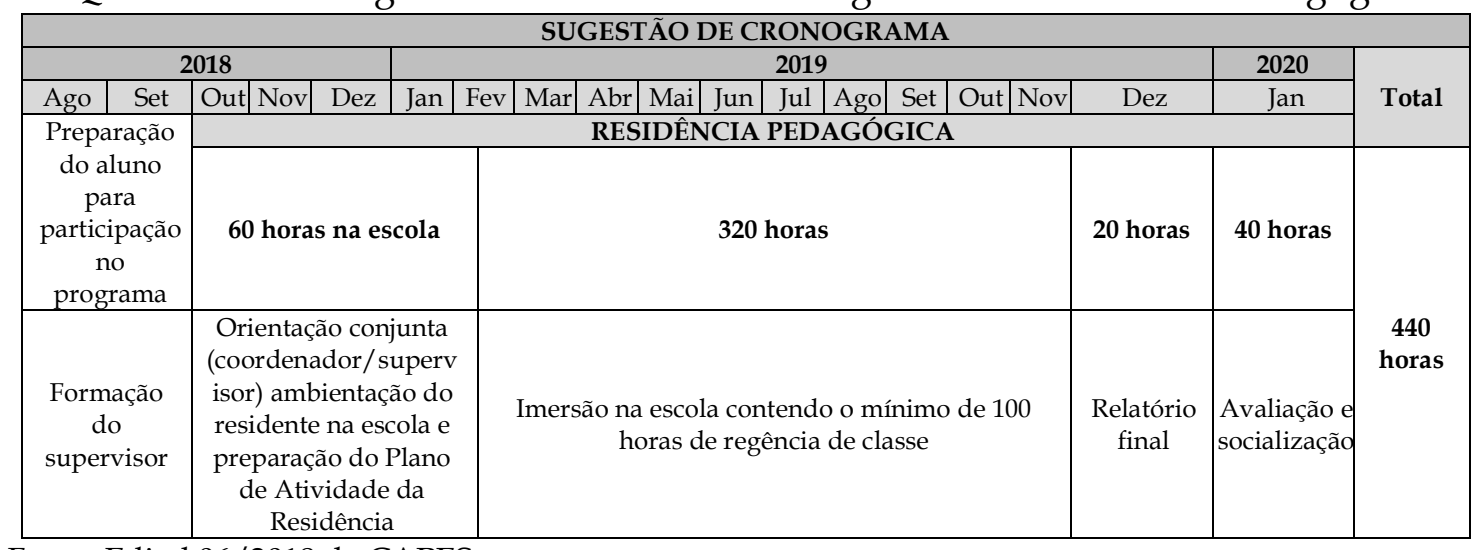

Fonte: Edital 06/2018 da CAPES. 
O Programa de Residência Pedagógica também tem funcionado para expor os avanços e a novas possibilidades do fazer pedagógico inovador. Ademais, também tem apresentado as debilidades e dificuldades dos processos de formação nas IFES e nas escolas estaduais e federais.

Avanços e benefícios da atuação dos professores/colaboradores e dos residentes do PRP do curso de licenciatura em informática/Ipanguaçu.

- Desenvolvimento significativo da interação dos residentes com a comunidade escolar, familiarização com as questões didático-pedagógicas e a relação direta com o docente colaborador;

- Melhoria nos desempenhos dos estudantes da educação básica devido a presença e a permanência dos residentes;

- Aprimoramento das técnicas de ensino por meio das necessidades de adequação de conteúdos e da adaptação de materiais de ensino e pesquisa;

- Ampliação de níveis de organização e responsabilidade oriundos das jornadas de reuniões, planejamentos, elaboração de artigo e compromisso com os horários de aulas na escola-campo.

Dificuldades de atuação dos professores/colaboradores e de residentes do PRP do curso de licenciatura em informática/Ipanguaçu.

- Dificuldade para adequar os horários dos docentes preceptores para atendimento dos residentes. Isso demonstra a sobrecarga dos profissionais da escola pública que ali trabalham;

- Necessidade de ministrar as aulas numa perspectiva interdisciplinar. Essa problemática ocorre devido à maioria das escolas não ter um professor específico de informática. Assim, os residentes precisam trabalhar com professores de outras áreas;

- Problemas nas condições estruturais de algumas escolas-campo. Ausência de material físico para prover as aulas.

\section{O PRP EM ESCOLA-CAMPO IFRN IPANGUAÇU}

O Programa de Residência Pedagógica compõe o projeto pedagógico do curso de licenciatura em informática do IFRN/Ipanguaçu que se desdobra no desenvolvimento de estágios de imersão nas escolas estaduais e na escola federal.

Conforme pontuamos, o Programa tem se consolidado como espaço de aprendizagem mútua entre o curso de informática e as escolas de aplicação. Os residentes são recebidos pelas escolas-campos e pelos professores orientadores que os supervisionam, os auxiliam e os acompanham em sua jornada de descobertas e imanência no ensino-aprendizagem. 
Os professores do curso de informática do IFRN também exercem um papel fundamental na formação, orientação, acompanhamento e desenvolvimento dos residentes e professores das escolas receptoras.

Neste sentido, ocorre uma simbiose entre o local de estudos e o local de aplicação dos conteúdos. O PRP cria articulação em regime de colaboração que visa dividir responsabilidades na formação dos estudantes. Isso beneficia, para além dos residentes no projeto formativo, centenas de estudantes que estão na base do processo da escola-campo de educação básica.

O PRP tem possibilitado a capacidade de refletir sobre as práticas, de criticar e melhorar o agir docente. Nas trilhas de Freire, entendemos que:

(...) na formação permanente dos professores, o momento fundamental é o da reflexão crítica sobre a prática. É pensando criticamente a prática de ou de ontem que se pode melhorar a próxima prática. O próprio discurso teórico, necessário à reflexão crítica, tem de ser de tal modo concreto que quase se confunda com a prática. O seu "distanciamento" epistemológico da prática enquanto objeto de sua análise, deve dela "aproximá-lo" ao máximo. Quanto melhor faça esta operação tanto mais inteligência ganha da prática em análise e maior comunicabilidade exerce em torno da superação da ingenuidade pela rigorosidade. (FREIRE, 1996, p.18).

Freire reflete que a prática docente deve ser enriquecida por um processo de reflexão crítica. Este seria o caminho para aprimorar as próximas práticas e avaliar de forma constante se o discurso está aliado à ação constituída em uma práxis educativa. Assim, os saberes acumulados do esforço prático servem pra orientar de maneira significativa a reflexão constante que cabe a formação do docente em atividade e do futuro docente. Portanto, reflexão crítica deve ser o norte que se busca na formação inicial e continuada de licenciandos e professores.

A tabela a seguir apresenta a estrutura organizacional institucional do PRP no IFRN Ipanguaçu, semestre 2019.2.

Quadro 3: Impactos do PRP no IFRN Ipanguaçu.

\begin{tabular}{|c|c|c|c|c|}
\hline $\begin{array}{c}\text { Estudantes de } \\
\text { educação básica } \\
\text { atingidos pelo } \\
\text { programa }\end{array}$ & $\begin{array}{c}\text { Professores } \\
\text { colaboradores }\end{array}$ & Preceptor & $\begin{array}{c}\text { Orientador } \\
\text { (coordenador } \\
\text { local) }\end{array}$ & $\begin{array}{c}\text { Bolsas } \\
\text { concedidas } \\
\text { aos } \\
\text { residentes }\end{array}$ \\
\hline + de 150 & 5 & 1 & 1 & 7 \\
\hline
\end{tabular}

No IFRN Ipanguaçu foram dezenas de horas aulas assistidas e outras dezenas ministradas e planejadas pelos residentes com orientação direta dos professores orientadores, proporcionando a ambientação, a imersão no contexto da sala de aula e, de maneira particular, a prática da regência.

Em Ipanguaçu, o PRP trouxe consigo as possibilidades de ampliação dos horizontes das práticas educativas, pois, consonante o projeto avançou os níveis de 
comprometimento e de aprendizagem também se alargam, já que docentes colaboradores, orientadores, residentes, preceptores e estudantes beneficiados pelo processo estão numa troca semanal de feedbacks (num conjunto de encontros que são compostos por aulas, planejamentos, minicursos, reuniões formativas, preparatórias e decisórias).

A diversidade de mediações transformou o espaço escolar em um grande laboratório formativo em que o ensino e a aprendizagem desenvolveram os sujeitos.

$\mathrm{Na}$ tabela a seguir podemos visualizar os impactos pedagógicos proporcionados pelo PRP no semestre 2019.2

Quadro 4: impactos pedagógicos do PRP no IFRN Ipanguaçu.

\begin{tabular}{|c|c|c|c|c|c|}
\hline $\begin{array}{c}\text { Minicursos } \\
\text { ofertados }\end{array}$ & $\begin{array}{c}\text { Artigos } \\
\text { para } \\
\text { publicação } \\
\text { (em } \\
\text { execução) }\end{array}$ & $\begin{array}{c}\text { Aulas } \\
\text { ministradas } \\
\text { pelos } \\
\text { residentes }\end{array}$ & $\begin{array}{c}\text { Planejamentos } \\
\text { realizados } \\
\text { (em } \\
\text { horas/média) }\end{array}$ & $\begin{array}{c}\text { Reuniões } \\
\text { executadas } \\
\text { (em horas) }\end{array}$ & $\begin{array}{c}\text { Turmas } \\
\text { beneficiadas }\end{array}$ \\
\hline 1 & 5 & + de 32 & 30 & + de 40 & $\begin{array}{c}3 \\
\text { subsequentes } \\
2 \text { integrados }\end{array}$ \\
\hline
\end{tabular}

Fonte: autor.

A compreensão do grande impacto pedagógico na estrutura da escola campo e no seu dia a dia (percebida por nós) é determinante para perceber a contribuição que o PRP gerou no último ano, e de forma central, no semestre 2019.2, em que o desenvolvimento da prática se acentuou com a inserção das atividades de planejamento, a possibilidade de se ministrar minicurso e aulas elaboradas e supervisionadas pelos professores preceptores.

Percebemos que houve melhorias nos índices das turmas e das aulas dos professores beneficiados pelo Programa. Em outras palavras, percebemos a elevação de forma significativa do rendimento dos estudantes da educação básica que puderam recorrer aos residentes para auxílio e troca de experiências de aprendizagem.

No decorrer do ano de 2019, o PRP no IFRN campus Ipanguaçu conseguiu desenvolver uma série de atividades de cunho didático, acadêmico e profissional que caminharam, conforme pontuamos no quadro acima, na direção da tríade: ensino, pesquisa e extensão.

O programa intensificou a elaboração de trabalhos conjuntos e atividades formativas advindas do tempo das reuniões, dos trabalhos acadêmicos produzidos, das metodologias aplicadas e avaliadas, dos seminários de integração e, de maneira peculiar, da prática do ensino. 


\section{CONSIDERAÇÕES FINAIS}

O Programa de Residência Pedagógica representa nos últimos anos uma tentativa de inserir milhares de estudantes, das mais diversas licenciaturas espalhadas pelo Brasil, na realidade da escola pública e assim proporcionar o encontro entre licenciandos e o trabalho docente.

O PRP tem 1) aproximado as universidades e as escolas públicas; 2) traçado perspectivas formativas que beneficiam a futura atuação dos profissionais da educação; 3) permitido o diálogo entre teoria e prática; 4) vivências do ambiente escolar, entre outros.

Concluímos que é no dia a dia escolar que surgem as dificuldades e as possibilidades de superação. É no seio do ambiente profissional que se pode visualizar as falhas formativas, experienciar, criar e aplicar novas metodologias. É no diálogo entre professores orientadores, preceptores, residentes, professores colaboradores e membros da comunidade escolar que se gestam os horizontes formativos. É na imersão que surge o potencial criativo para alcançar os resultados.

A escola-campo IFRN Ipanguaçu ao reunir residentes, preceptores, orientadores e comunidade escolar, em 2019, presenciou fortes experiências pedagógicas nos âmbitos do ensino, pesquisa e extensão. Foram largas as contribuições dos debates, reuniões, aulas, seminários de integração, conversas de corredores, partilha de desafios, entre outras ações.

Deferimos que o Programa tem alterado positivamente a dinâmica e as rotinas dos cursos desta escola por meio de práxis assertivas. O benefício central é a formação humana integral dos futuros docentes que estão em formação, assim como dos demais atores presentes no ciclo profícuo de formação.

\section{REFERÊNCIAS}

CAPES. Edital 06/2018. Disponível em: https:// www.capes.gov.br/images/stories/download/editais/01032018-Edital-62018-Residencia-pedagogica.pdf. Acesso em: 20/10/2019.

FREIRE, Paulo. PEDAGOGIA DA AUTONOMIA: Sabres necessários à prática educativa. São Paulo: Paz e Terra, 1996. p. 54.

GUEDES, Cavalcante Neide. Tecendo diálogos, ressignificando saberes: o tornar-se professor (a). 2014. Disponível em: https://docplayer.com.br/44356-Tecendodialogos-ressignificando-saberes-o-tornar-se-professor-a.html\#show_full_text Acesso em: 20/10/2019.

HARVEY, David. O NEOLIBERALISMO: história e implicações. São Paulo: Loyola, 2008. 
MARTINS, Iara Saraiva. Pronatec: a estratégia do partido dos trabalhadores para a inserção no trabalho precário e atendimento das demandas produtivas do capitalismo contemporâneo no Brasil. 2015. Dissertação (Pedagogia) - UFC, Fortaleza, 2015.

PIMENTA, Selma Garrido. Formação de professores - saberes da docência e identidade do professor. Nuances, vol. III, p. 5-14, 1997.

Lima. Maria Socorro Lucena. Estágio e docência: diferentes concepções. Revista Poíesis. vol. 3, números 3 e 4, p. 5-24, 2005/2006.

SILVA, Katia Augusta Curado Pinheiro. CRUZ, Shirleide Pereira. A Residência Pedagógica na formação de professores: história, hegemonia e resistências. Revista Momento: diálogos em educação, v. 27, n. 2, p. 227-247, mai./ago, 2018.

TARDIF, Maurice. Saberes docentes e formação profissional. Petrópolis: Vozes, 2002.

TAVARES, Andrezza Maria Batista do Nascimento. SANTOS, Luiz Antonio da Silva. 2019. Contribuições formativas do programa de residência pedagógica para as licenciaturas do IFRN. In: Nascimento, Jose Mateus. Silva, Jose Moises Nunes (org.). Educação Profissional e contradições sociais: pontos e contrapontos. Natal: Famen, 2019. p. 153-164. 